\title{
Farmer's Empowerment by Farm Services Centers: A Pedagogic Approach for Sustainable Development
}

\author{
Muhammad Zafarullah Khan ${ }^{1 *}$, Rehmat Ullah ${ }^{1}$, Asif Nawaz ${ }^{1}$ and Ejaz Ashraf ${ }^{2}$
}

${ }^{1}$ Department of Agricultural Extension Education and Communication, The University of Agriculture Peshawar, Khyber Pakbtunkhwa, Pakistan; ${ }^{2}$ Department of Agricultural Extension and Rural Development, University College of Agriculture, University of Sargodha, Sargodha, Pakistan.

Abstract The present study was carried out in Khyber Pakhtunkhwa province during 2014 in order to investigate about the performance of Farm Services Centers in the empowerment of farmers towards the sustainable development. Five districts of Khyber Pakhtunkhwa such as Mansehra, Dir Lower, Swat, Dera Ismail Khan and Swabi were the sampled districts and 80 farmers registered with Farm Services were randomly selected from each district. Thus, sample size was making a total of 400 respondents. Primary data were collected with the help of pre-tested interview schedule through personal interview method. The results of this research study revealed that affinity toward Farm Services Centers were bulk of the educated, middle aged and small landholding farmers. Maximum of the respondents had above 20 years of farming experience. A rapid increase in the registration of farmers with Farm Services Centers was found in the last five years. Chi-square results indicated highly significant association $(\mathrm{P} \leq 0.05)$ between the duration of registration with Farm Services centers, fertilizers and farm machinery provided to the respondents. Farm Services Center's performed their commitment very well with respect to empowerment of farmers in different agrarian practices like decision making, farm management, varietal selection, management of weed, and selection of fertilizer. Private agricultural companies were also playing their role in technological breakthroughs. It is therefore, suggested that these agricultural companies must be allowed for demonstration to train farmers on their innovations under Farm Services Center's. Received | January 31, 2017; Accepted | February 13, 2018; Published | March 15, 2018

*Correspondence | Muhammad Zafarullah Khan, Department of Agricultural Extension Education and Communication, The University of Agriculture Peshawar, Khyber Pakhtunkhwa, Pakistan; Email: drzafar@aup.edu.pk

Citation | Khan, M.Z., R. Ullah, A. Nawaz and E. Ashraf. 2017. Farmer's empowerment by farm services centers: A pedagogic approach for sustainable development. Sarhad Journal of Agriculture, 34(2): 225-232.

DOI | http://dx.doi.org/10.17582/journal.sja/2018/34.2.225.232

Keywords | Decision making, Farm services center, Fertilizer, Seed companies and Weed management

\section{Introduction}

A griculture has been, and is, a highly regulated activity in Pakistan. While farmers are increasingly subject to food safety and environmental regulations, the objective for sustainable development in agriculture is of much concern with market price stability and farmer's income support and provision of domestic subsidies. To accumulate terrific agriculture, growth section must be envisioned with the modern capacity building production strategies, increasing competitiveness and providing friendly environment for local trade (Gabre-Madhin and Johnston, 2002). The above factors will convict more investors in this sector and will sharply meet the domestic demand of better quality food and surplus for export (Javid et al., 2010). There is a terrible need of the latest agricultural technology to achieve food security. The latest techniques of agriculture should replace the orthodox methods of farming. In order to achieve the above mentioned goals, many extension strategies have been tested so far but none of them were effectual in inJune 2018 | Volume 34 | Issue 2 | Page 225 
creasing agricultural productivity. The Khyber Pakhtunkhwa government thus started a Farm Services Centers (FSC) approach in 2001 in 23 districts of the entire province to make the farmers capable in various aspects of farming in their own milieu and financial assets with an equal share from the government (Dad, 2004).

The government of Khyber Pakhtunkhwa established these FSCs with the fundamental intention for the provision of agricultural inputs of good quality, improved transfer of technology and well-organized system of marketing. Moreover, it also aimed to provide assistance to the farmers in order to solve their own conflicts and consequently for the improvement of farmers with the help of agricultural officer. For the empowerment of the farmers, they were granted an equal share to the amount they have collected in order to offer more autonomy in their roles and responsibilities in terms of executing and managing the activities under FSCs themselves. The FSCs were established based on the idea that usually farmers had lack of resources. Therefore, the government initiated this strategy of FSC to bring them collectively where they will be made capable to efficiently utilize their resources. Farmers can get membership with FSC by payment of Rs. 100 as enrolment fee and Rs. 500 as membership fee. The government provides a matching grant equal to the farmers share (Dad et al., 2007).

\section{Objectives of FSCs}

- To amplify access of farmers towards good quality farm inputs probably at their doorstep on minimum possible rates.

- To develop the skills of farming community regarding planning, needs assessment and management of their farms.

- To establish the linkages of the farmers with markets, line agencies and services providers.

- To made the farmers capable to accomplish seed production system and administer the distribution of inputs effectively.

The FSCs provide the services to the farming community such as secure rights and interests of farmers, upgrade farmers' knowledge and skills, awareness regarding advances in farming, boost crop yield, provision of certified seeds, build up economy of rural areas, pesticides, fertilizers and services regarding animal husbandry. The FSCs also provide latest farm machinery such as tractor, sheller, thresher, rotavator, lazer leveler etc and also provide expertise about the latest technology. Moreover the FSCs facilitate the registered farmers to take benefits from the laboratories maintained and developed by government on the lowest possible rates.

Shah et al. (2016) argued that beneficiary farmers of FSC had higher productivity in terms of crops, livestock and milk. Timely availability of improved seeds, fertilizers and pesticides along with latest machinery had significantly increased farmers' income. Ullah et al. (2015) reported that one year of increase in duration of MFSC membership increased sugarcane yield up to $12.84 \mathrm{~kg} / \mathrm{ha}$ and $45 \mathrm{~kg} / \mathrm{ha}$ in wheat. Khan et al. (2017) revealed that farmers registered with FSCs were more inclined towards cultivation of vegetables on larger land and also achieved higher yield due to their effective services. Keeping in view the significance of FSC approach, the study in hand was carried out to assess the execution of FSC in strengthening of farmers towards the sustainable development.

\section{Materials and Methods}

\section{Universe of study}

The Khyber Pakhtunkhwa province is located between 31 to $37^{\circ}$ North and 70 to $74^{\circ}$ East. The geographic area of Khyber Pakhtunkhwa is 10.17 million ha that constitute $12.8 \%$ of the total geographic area of Pakistan (Khattak, 2008). Five districts of Khyber Pakhtunkhwa such as Dera Ismail Khan, Swat, Dir Lower, Mansehra and Swabi were selected for the present study after comprehensive discussion with experts.

\section{Research design}

This study utilized Descriptive Survey Research Design. The fundamental idea of the current study was to scrutinize the farmers' empowerment by FSCs, therefore descriptive research design (Khooharo, 2008) was chosen.

\section{Sample size and sample selection}

About 80 registered farmers with FSCs from each of the five chosen sampled districts were randomly selected constituting an overall sample of 400 for this study. The agriculture extension department of each sampled district was consulted to obtain the entire list of registered farmers with FSCs in the respective districts. Random numbers were generated with the help of statistical software (SPSS) for the selection of sample respondents. 
Data collection tool (Interview schedule)

A well-structured interview schedule containing both open and close-ended questions was prepared for the primary data collection. Before the actual primary data collection, an interview schedule was pre-tested on 5 farmers of each selected districts and the required changes were incorporated. The coefficient of Cronbatch alpha (Cronbach, 1951) was calculated in order to check the reliability of the research instrument with the help of SPSS and the calculated Cronbatch alpha was 0.82 .

\section{Analysis of data}

The collected primary data was tabulated and analyzed with the help of SPSS and was presented in simple percentages. Furthermore, Chi-square test was performed to check association among various variables.

Table 1: Demographic characteristic of the respondents.

\section{Variables}

Age (In years)$$
\text { A }
$$

Education (In Years)

Total Landholding

(in acres)

Farming Experience (in years)

$\begin{array}{llll}\text { years) } & 21-40 & 151 & 37.8 \\ & 41+ & 29 & 7.2 \\ & \text { Total } & 400 & 100 \\ \text { Major source of Income } & \text { Agriculture } & 302 & 75.5 \\ & \text { Business } & 46 & 11.5 \\ & \text { Govt. Job } & 41 & 10.2 \\ & \text { Other } & 11 & 2.8 \\ & \text { Total } & 400 & 100.0 \\ \text { Duration of Registration } & <=5 & 220 & 55 \\ \text { With FSC } & 6-10 & 121 & 30.2 \\ & 10+ & 59 & 14.8 \\ & \text { Total } & 400 & 100\end{array}$

Results and Discussion

\section{Respondent's profile}

For any sustainable approach, the demographic characteristics of the farmers such as education, age, farming background and landholding are considered as very necessary parts in their response and mindfulness towards improved agricultural innovations. Research studies (Saddi et al., 2008; Jensen et al., 2009) reported that demographic factors had impact upon other factors related to diverse aspects which seems somewhat rational. Table 1 shows the data regarding respondents' age and results show that maximum of the respondents (44\%) had their age in $31-50$ years while (34.2\%) of the respondents fall in 51-70 years of age category. Almost $19 \%$ of the respondents had less than 31 years of age while a small portion of respondents $3 \%$ had recorded age above 70 years. The current results predict that in the study areas, mostly the middle aged respondents had affinity towards FSCs. According to Singh and Singh (2000), education is a prospective foundation that can assist the farmers regarding their knowledge about utilization of agricultural technologies. The results in Table 1 further revealed that almost $36 \%$ of the respondents had six to 12 years of schooling followed by the respondents $32.2 \%$ that had formal schooling of above 13 years while almost same number of respondents $32.2 \%$ had less than six years schooling. The current results are in contrast with those of Cheema (2004) who found that almost $58 \%$ of the respondents had five years of schooling. The results in Table 1 showed that less than half $44.5 \%$ of the respondents had landholdings of 5 to 50 acres followed by respondents who had a landholding of less than 5 acres (42\%). The respondents with $51-100$ acres of land were $7.5 \%$ and above 100 acres of landholding were $6 \%$. The current results accomplished that petite landholding seems to be a major attribute of the farmers. Results in Table 1 revealed that greater than half of the respondents $55 \%$ had upto 20 years of farming experience followed by $38 \%$ of the respondents that had experience of 21 to 40 years in farming whereas $7 \%$ of the respondents had above 40 years of farming experience. Data in Table 1 showed that agriculture was the top most source of livelihood of almost $76 \%$ of the respondents and about $11 \%$ of the respondents had business as their source of income. Merely $10 \%$ of the respondents argued that government job is the source of their income while a minute number of respondents $3 \%$ get their livelihood from other sources. These results 
Table 2: Sources of agricultural information.

\section{Sources of Information}

Extent of Information availed from FSC

Extent of information availed from Agriculture Extension

Extent of information you avail from Fellow Farmers

Extent of information you avail from Agriculture Research

Extent of information you avail from TV

Extent of information you avail from Farmers Meetings

Extent of information you avail from Radio

Extent of information you avail from Input Dealers

Table 3: Distribution of respondents regarding information dissemination method used In FSCS.

$\begin{array}{llll}\text { Contact Method } & \text { Scale } & \text { Count } & \text { \%age } \\ \text { Individual Contact Method } & \text { Very Low } & 50 & 12.5 \\ & \text { Low } & 19 & 4.8 \\ & \text { Medium } & 50 & 12.5 \\ & \text { High } & 110 & 27.5 \\ & \text { Very High } & 171 & 42.8 \\ \text { Group Contact Method } & \text { Very Low } & 121 & 30.2 \\ & \text { Low } & 17 & 4.2 \\ & \text { Medium } & 32 & 8 \\ & \text { High } & 97 & 24.2 \\ & \text { Very High } & 133 & 33.2 \\ \text { Mass Contact Method } & \text { Very Low } & 306 & 76.5 \\ & \text { Low } & 14 & 3.5 \\ & \text { Medium } & 12 & 3 \\ & \text { High } & 65 & 16.2 \\ & \text { Very High } & 3 & 0.8\end{array}$

are in line with those of Verma et al. (2013) viewed that agriculture was the major source of $53.3 \%$ of the respondents. The results further showed that maximum $55 \%$ of the respondents were registered with FSC 5 years ago while about $30 \%$ of the respondents had registered with FSC from 6 to 10 years. Almost 15\% of the respondents reported that they had registered with FSC more than 10 years ago (Table 1 ). Awareness is the initial phase in the adoption process and for this drive agricultural extension is one of the methods accessible to help farmers for their capacity building. It is an extraordinary service as it offers access to small farmers and rural poorer living a long way from the urban areas along with transfer of technology. The outcomes demonstrated the finest communication fidelity and of change agents that they not just aware the farmers about the presence of FSC additionally incite to get enroll with FSCs for better help and learning

$\begin{array}{lllll}\text { Very Low } & \text { Low } & \text { Medium } & \text { High } & \text { Very High } \\ 22.5 & 4 & 5.8 & 9.8 & 58 \\ 29 & 6 & 7.8 & 10.2 & 47 \\ 22.2 & 3.2 & 14.5 & 14.8 & 45.2 \\ 63.5 & 6.5 & 9 & 4 & 17 \\ 90.5 & 2 & 2.8 & 2.2 & 2.5 \\ 59.2 & 2.2 & 7.5 & 8.8 & 22.2 \\ 91.5 & 3.2 & 2.2 & 1.2 & 1.8 \\ 30.5 & 1 & 10.2 & 14.8 & 43.5\end{array}$

of scientific practices regarding modern agriculture.

Extent of information availed from various sources

FSC is an agriculture extension approach that is not only responsible for information dissemination but also to bring about desirable change in farmers' behaviour. The respondents were asked about the information sources available for them in the study area, and their responses were presented in Table 2. The results revealed that information availed from FSC were reported by $58 \%, 9.8 \%$ and $5.8 \%$ of the respondents as very high, high and medium respectively on five point likert scale. This means that about $74 \%$ of the respondents contacted with FSC members for information regarding farming activities. Agriculture extension as an information source was rated by $7.8 \%$, $10.2 \%$ and $47 \%$ of the respondents on five point likert scale as medium, high and very high respectively. Fellow farmer was also the important source of information because of easily available and less cost of travelling as $14.8 \%$ of the respondents rated high and $45.2 \%$ rated very high on likert scale. Input dealers were also playing their role effectively in dissemination of information as indicated by $14.8 \%$ and $43.5 \%$ of the respondents as high and very high respectively. Agriculture research was not a good source of information as only $17 \%$ of the respondents rated very high on likert scale. However TV, Farmers meeting and radio were the most least ranked sources of information by the respondents. The results concluded that FSC, agriculture extension, fellow farmers and inputs dealers were the most prominent sources of information for the respondents in the study area.

\section{Methods used for dissemination of information}

The respondents were probed during the survey to investigate about the method that FSCs used for the dissemination of information among them and their views are drawn in Table 3 . The results revealed that 
almost $70 \%$ of the respondents rated individual contact method as high and very high that FSCs used for information dissemination. The results further revealed that group contact method and mass contact method was rated as high and very high by $57 \%$ and $17 \%$ of the respondents, respectively. During the field survey, it was observed that mostly the respondents visits the FSCs for the required information regarding agriculture that why the respondents rated individual contact method the most used method for dissemination of information. However the FSCs also arranged various types of trainings for the farmers in order to solve their problems but these are not regularly arranged. Mass contact method was very rarely used by FSCs to disseminate information among the farming community.

Table 4: Provision of inputs by FSCs.

$\begin{array}{llll}\text { Inputs provided } & \text { Scale } & \text { Count } & \text { \%age } \\ \text { Provision of Seed as inputs } & \text { Very Low } & 37 & 9.2 \\ & \text { Low } & 19 & 4.8 \\ & \text { Medium } & 50 & 12.5 \\ & \text { High } & 32 & 8 \\ & \text { Very High } & 262 & 65.5 \\ \text { Provision of Fertilizer as inputs } & \text { Very Low } & 41 & 10.2 \\ & \text { Low } & 19 & 4.8 \\ & \text { Medium } & 44 & 11 \\ & \text { High } & 47 & 11.8 \\ & \text { Very High } & 249 & 62.2 \\ \text { Provision of Pesticide as inputs } & \text { Very Low } & 164 & 41 \\ & \text { Low } & 37 & 9.2 \\ & \text { Medium } & 24 & 6 \\ & \text { High } & 11 & 2.8 \\ & \text { Very High } & 164 & 41 \\ \text { Provision of Farm Machinery as } & \text { Very Low } & 131 & 32.8 \\ & \text { Low } & 16 & 4 \\ \text { inputs } & \text { Medium } & 108 & 27 \\ & \text { High } & 31 & 7.8 \\ & \text { Very High } & 114 & 28.5\end{array}$

\section{Provision of inputs by FSCs}

The FSCs provides seeds, fertilizers, pesticides and machinery to the registered farmers as shown in $\mathrm{Ta}$ ble 4 . The results revealed that majority of the farmers $65.5 \%$ ranked provision of seeds as very high on likert scale whereas $62.2 \%$ of the respondents reported provision of fertilizers as very high. Provision of pesticides was reported very high by $41 \%$ of the respondents on likert scale. Farm machinery was reported by
$28.5 \%$ of the respondents very high on likert scale while almost $33 \%$ of the respondents reported very low. It is clear from the results that FSCs did not provide the farm machinery satisfactorily therefore the government along with other inputs must pay special emphasis on provision of farm machinery to the farming community. During the survey it was found that farmers had adopted steadiness in fertilizer application, good quality seeds, latest machinery and application of pesticides to acquire potential yield. Moreover less amount of inputs and also due to less number of machinery with FSCs and their provision for short duration were the major issues observed during the data collection. It can be associated with the fact that due to the availability of machinery for less time, it is difficult for the farmers to cover all the field operations because of greater landholdings. Accordingly the greater part of the farmers got less opportunity to book the machinery for their field operations and for an excessive amount of time. In order to address the above mentioned issues, the FSCs ought to bring more stakeholders on board to minimize the financial burden on FSCs. Mesic et al. (2007) reported that the yield increases when inputs were made easily available.

\section{Association among duration of registration and provision of inputs by FSCs}

Chi-square test was applied to check the association between inputs provided by FSCs and duration of registration and the results were shown in Table 5. Table 5 revealed highly significant association $(\mathrm{P} \leq 0.01)$ among the farm machinery provided by FSCs and duration of registration with FSC. The results showed that with increase in duration of registration, the provision of machinery got decreased which showed an inverse association. It was found during the field survey that respondents that had registered with FSCs for more years are utilizing the machinery available on rent instead of FSCs' machinery that is why an inverse association exists. In contrast, the newly registered farmers with FSCs were more enthusiastic towards the utilization of FSC's machinery. Significant association $(\mathrm{P} \leq 0.01)$ was observed among the duration of registration and fertilizers provided by FSCs (Table 5). It might be due to the fact that the newly registered farmers had received the fertilizers more the old member of the FSCs. The results further showed that there was non-significant association among duration of registration and both seeds and pesticides provision by FSCs which concluded that 
Table 5: Association among registration duration and inputs provision by FSCs.

\begin{tabular}{|c|c|c|c|c|c|c|c|c|}
\hline \multirow[t]{3}{*}{ Inputs } & \multirow[t]{3}{*}{ Scale } & \multicolumn{6}{|c|}{ Since how many years you are registered } & \multirow[t]{3}{*}{ p-value } \\
\hline & & \multicolumn{2}{|l|}{$<=5$} & \multicolumn{2}{|l|}{$6-10$} & \multicolumn{2}{|l|}{$10+$} & \\
\hline & & Count & $\%$ & Count & $\%$ & Count & $\%$ & \\
\hline \multirow[t]{5}{*}{ Seed } & Very Low & 23 & 62.2 & 7 & 18.9 & 7 & 18.9 & \multirow[t]{5}{*}{0.093} \\
\hline & Low & 13 & 68.4 & 3 & 15.8 & 3 & 15.8 & \\
\hline & Medium & 33 & 66 & 15 & 30 & 2 & 4 & \\
\hline & High & 16 & 50 & 8 & 25 & 8 & 25. & \\
\hline & Very High & 135 & 51.5 & 88 & 33.6 & 39 & 14.9 & \\
\hline \multirow[t]{5}{*}{ Fertilizer } & Very Low & 32 & 78 & 6 & 14.6 & 3 & 7.3 & \multirow[t]{5}{*}{0.043} \\
\hline & Low & 14 & 73.7 & 3 & 15.8 & 2 & 10.5 & \\
\hline & Medium & 26 & 59.1 & 14 & 31.8 & 4 & 9.1 & \\
\hline & High & 23 & 48.9 & 15 & 31.9 & 9 & 19.1 & \\
\hline & Very High & 125 & 50.2 & 83 & 33.3 & 41 & 16.5 & \\
\hline \multirow[t]{5}{*}{ Pesticide } & Very Low & 100 & 61 & 36 & 22 & 28 & 17.1 & \multirow[t]{5}{*}{0.064} \\
\hline & Low & 23 & 62.2 & 10 & 27 & 4 & 10.8 & \\
\hline & Medium & 13 & 54.2 & 6 & 25 & 5 & 20.8 & \\
\hline & High & 4 & 36.4 & 5 & 45.5 & 2 & 18.2 & \\
\hline & Very High & 80 & 48.8 & 64 & 39 & 20 & 12.2 & \\
\hline \multirow[t]{5}{*}{ Farm Machinery } & Very Low & 84 & 64.1 & 26 & 19.8 & 21 & 16 & \multirow[t]{5}{*}{0.000} \\
\hline & Low & 11 & 68.8 & 4 & 25 & 1 & 6.2 & \\
\hline & Medium & 32 & 29.6 & 59 & 54.6 & 17 & 15.7 & \\
\hline & High & 19 & 61.3 & 5 & 16.1 & 7 & 22.6 & \\
\hline & Very High & 74 & 64.9 & 27 & 23.7 & 13 & 11.4 & \\
\hline
\end{tabular}

Table 6: Linkages of farmers developed by FSCs with inputs agencies.

$\begin{array}{llll}\text { Input Agencies } & \text { Scale } & \text { Count } & \text { \%age } \\ \text { Seed Companies } & \text { Very Low } & 317 & 79.2 \\ & \text { Low } & 14 & 3.5 \\ & \text { Medium } & 16 & 4 \\ & \text { High } & 8 & 2 \\ & \text { Very High } & 45 & 11.2 \\ \text { Pesticide Companies } & \text { Very Low } & 321 & 80.2 \\ & \text { Low } & 12 & 3 \\ & \text { Medium } & 14 & 3.5 \\ & \text { High } & 9 & 2.2 \\ & \text { Very High } & 44 & 11 \\ \text { Farm Machinery Industry } & \text { Very Low } & 345 & 86.2 \\ & \text { Low } & 6 & 1.5 \\ & \text { Medium } & 16 & 4 \\ & \text { High } & 7 & 1.8 \\ & \text { Very High } & 26 & 6.5\end{array}$

seeds and pesticides were provided to the farmers irrespective of their registration duration with FSCs.

\section{Linkages developed with inputs agencies by FSCs}

Since creation of farmers' linkages with the input agencies is one of the fundamental aims of FSCs, therefore respondents were asked about their linkages made by FSCs with input agencies and their responses were presented in Table 6. Almost 80\% of the respondents reported that FSC did not build their linkages with seed companies whereas $11.2 \%$ of the respondents rated very high their linkages with seed companies build through FSCs. Majority of the respondents $80.2 \%$ had reported that FSCs did not developed their linkages with pesticides companies whereas $11 \%$ of the respondents rated very high their linkages with pesticide companies established through FSCs. A clear majority of the respondents 87.2\% reported that FSCs did not create their linkages with farm machinery industry. The present results conclude that FSCs did not fulfill its obligation regarding development of farmers' linkages with the input agencies.

\section{Empowerment by FSCs}

Empowerment can be defined as to fortify the farmers' capabilities in decision making about the effective 
Table 7: Empowerment of farmers by FSCs.

$\begin{array}{lllllll}\text { Empowerment } & \text { Very Low } & \text { Low } & \text { Medium } & \text { High } & \text { Very High } & \text { P-Value } \\ \text { Farm Management } & 30.5 & 2 & 3.5 & 4 & 60 & 0.315 \\ \text { Decision Making } & 35 & 1.8 & 2.2 & 4.8 & 56.2 & 0.137 \\ \text { Marketing of Produce } & 39.2 & 2.8 & 6.5 & 1.8 & 49.8 & 0.105 \\ \text { Selection of Better Varieties } & 30.2 & 5.2 & 3.5 & 4.2 & 56.8 & 0.192 \\ \text { Weed Management } & 30.2 & 2.8 & 4.8 & 5.5 & 56.8 & 0.230 \\ \text { Water Management Practices } & 34.5 & 4.8 & 5 & 3 & 52.8 & 0.209 \\ \text { IPM } & 35.5 & 4.2 & 6 & 2.5 & 51.8 & 0.144 \\ \text { IDM } & 36.2 & 3.2 & 6.8 & 2.2 & 51.5 & 0.139 \\ \text { Food Preservation Techniques } & 40.2 & 19 & 2.5 & 3.5 & 34.8 & 0.000 \\ \text { Extension Methods } & 34 & 2.8 & 4.5 & 20 & 38.8 & 0.02 \\ \text { Fertilizer Selection } & 31 & 2.5 & 4 & 5.8 & 56.8 & 0.243 \\ \text { Time of Sowing } & 30.8 & 5.5 & 2.2 & 4 & 57.5 & 0.072 \\ \text { Organic Farming } & 37 & 3.5 & 2 & 8.2 & 49.2 & 0.05 \\ \text { Need Based Technology } & 32.5 & 1.5 & 9.2 & 4.5 & 52.2 & 0.332\end{array}$

management and utilization of their resources. The respondents were probed during the field survey and their responses are shown in Table 7 . The results revealed that FSCs empowered maximum number $60 \%$ of the respondents regarding management of their farms whereas more than half of the respondents $56.2 \%$ were very highly empowered regarding decision making by FSCs in the study areas. The results further revealed that almost half of the respondents were empowered regarding marketing of their produce while each $56.8 \%$ of the respondents were very highly empowered in both selection of varieties and weed management on five point likert scale. The empowerment regarding water management, integrated pest management and integrated disease management were also satisfactory as reported by $53 \%$, $52 \%$ and $51.5 \%$. Very high empowerment regarding techniques of food preservation was reported by almost $35 \%$ of the respondents whereas $38.8 \%$ of the respondents were empowered very high in extension methods. Likewise empowerment in selection of fertilizer, sowing time, organic farming and need based technology by FSCs was also good as viewed by $56.8 \%, 57.5 \%, 49.2 \%$ and $52.2 \%$ of the respondents. These results discovered suitable domino effect regarding farmers' empowerment in a variety of practices. Chi-square test was applied further to check the association between empowerment of farmers by FSCs and duration of registration and the results are shown in Table 7 . The results showed a highly significant $(\mathrm{P} \leq 0.01)$ association among the duration of registration and empowerment in food preservation technique of the respondents. The result further shows that there were significant associations $(P \leq 0.05)$ between duration of registration and both extension methods and organic farming with significance level of 0.02 and 0.05 respectively. However, there were non-significant association among registration $\mathrm{du}-$ ration and empowerment in all other practices. This showed that irrespective of duration of registration, respondents were being empowered by FSCs in a variety of agricultural practices.

\section{Conclusions}

The current study concluded that bulk of the educated and middle aged farmers had inclination towards FSCs. Mainstream of the respondents had landholding of less than 5 acres and agriculture was their major source of income. About half of the respondents had above 20 years of farming experience. The farmers' registration with FSC had been increased in the recent years. The FSCs succeeded in their obligation regarding provisions of fertilizers, pesticides and improved seeds to the registered farmers. FSCs almost failed to create the linkages of farmers with the other line departments. FSCs performed their commitment up to greater extent in farmers' empowerment in selection of fertilizers, management of weeds, improved varieties selection, decision making and farm management. It is suggested that government might take initiatives for provision of funds on account of regular trainings arrangement, particular crop machinery and subsidized inputs. The private companies have to be permitted for demonstration to educate the farmers under FSC on their innovations. June 2018 | Volume 34 | Issue 2 | Page 231 
This paper was supported by the project of higher education commission on impact of farm services center approach on empowerment of farming community in Khyber Pakhtunkhawa-Pakistan, Project No.2873.

\section{Author's Contribution}

Muhammad Zafarullah Khan designed and supervised this research study. Rehmat Ullah and Asif Nawaz collected the data, wrote the manuscript and incorporate the suggestions of the reviewers. Ejaz Ashraf helped in data analysis. All authors finally approved the manuscript.

\section{References}

Cheema, F.S. 2004. A study into the working of extension field staff under public sector extension approach as perceived by the farmers of Faisalabad District. M.Sc. (Hons.) Thesis, Dept. of Agri., Ext., Univ. of Agri, Faisalabad, Pakistan.

Cronbach, L.J. 1951. Coefficient alpha and the internal structure of tests. Psychometrika16 (3): 297-334. https://doi.org/10.1007/BF02310555

Dad, A. 2004. History and development of farm service centers in Khyber Pakhtunkhwa: Structure of FSCs. Department of Agriculture, Government of Khyber Pakhtunkhwa.

Dad, A., Nizammi, E. Haldimann and R. Muhammad. 2007. FSCs: An alernative approach to realizing potential. Agriculture livestock, diary development and cooperatives, Government of Khyber Pakhtunkhwa.

Gabre-Madhin, E. and B. Johnston. 2002. Accelerating Africa's Structural Transformation: Lessons from Asia. In Jayne, T. S., IssasMinde and Gem Argwings-Kodhek (eds). 2002. Perspective on Agricultural Transformation: A view from Africa. Nova Science, New York.

Javid, Z.H., M. Farooq and H. Ali. 2010. Technology Transfer and Agricultural growth in Pakistan. Pak. J. Agric. Sci. 47(1):82-87.

Jensen, K.L., B.C. English and R.J. Menard. 2009. Livestock farmers' use of animal or herd health information sources. J. Ext., 47(1). [Online]
Khan, M.Z., S. Saud and A. Nawaz. 2017. To Study the effectiveness of farm services center regarding provision of agricultural inputs to its member farmers in Khyber Pakhtunkhwa, Pakistan. Sarhad J. Agric. 33(4): 519-525. https://doi. org/10.17582/journal.sja/2017/33.4.519.525

Khattak, S. 2008. Strengthening and restructuring of agricultural extension in NWFP. ASPL II consultant report Govt. of NWFP.

Khooharo, A.A. 2008. A Study of public and private sector pesticide extension and marketing services for cotton Crop. Ph.D. Dissertation, Department of Agricultural Education, Extension \& Short Courses, Sindh Agriculture University, Tandojam, Pakistan. pp. 42.

Mesic, Ž.Đ. Žutinic, and J. Wibberley. 2007. Rural technology transfer in transition economies in Croatia. Under Project Agro economic policy analysis of the new member states, the candidate states and the countries of the western Balkan. CEEC Agri. Policy.

Saadi, H., K.N. Mahdei and R. Movahedi, 2008. Surveying on wheat farmers' access and confidence to Information and Communication Channels (ICCs) about controlling Eurygaster integricepsin Hamedan province-Iran. Am. J. Agric. Biol. Sci. 3 (2): 497-501. [Online] http:// www.scipub.org/fulltext/AJAB/AJAB32497501.pdf

Shah, T., J. Tao, F. Liu, Abdullah, S. Ali and F. Shah. 2016. Comparing agricultural yield of member and non-member farmers of farm services centers in District Swat. ARPN J. Agric. Biol. Sci. 11(7): 283-289.

Singh, K. and Singh, K. 2000. Education, technology, adoption and agricultural productivity. Ind. J. Agric. Econ. 55(3): 473-489.

Ullah, R., M.Z. Khan, K. Ullah and T.M. Butt. 2015. Model farm services centers approach. an implication to boost Farmer's Yield. Agric. Sci. 6(1): 953-960. https://doi.org/10.4236/ as.2015.69092

Verma, N.K., D.K. Pandey and A.D. Upadhayay. 2013. Performance evaluation of fishery based self-help groups in West Tripura. Indian Res. J. Ext. Edu. 13 (3): 15-18. 